\title{
ON THE CHROMATES OF MERCURY, BISMUTH AND LEAD.
}

\author{
By Aevry J. Cox.
}

Received June 30, 1906.

WHEN neutral salts are hydrolyzed, the reaction is reversible. By hydrolysis a neutral salt yields an acid or an alkaline solution as an equilibrium product. A neutral chromate of a heavy metal yields an acid solution. When the equilibrium is attained at a constant temperature the acid solution must assume a definite concentration.

It has already been shown ${ }^{1}$ that the handbooks of chemistry contain descriptions, based on old literature, of basic salts that do not exist. There was formerly no theory to enable us to discriminate between a chemical compound and a mixture. Hence a great many mixtures have found their way into the literature as homogeneous substances.

In the previous paper only neutral and basic salts were studied. Of the acid salts of some of the heavy metals some have not been investigated at all and some but slightly. The use of the phase rule is also applicable to the identification and isolation of these.

The object of this study is to point out the conditions which are necessary to and which limit the existence of the chromates of the heavy metals-mercury, lead and bismuth.

The specific gravity of water solutions of chromium trioxide $\left(\mathrm{CrO}_{3}\right)$ of definite percentage composition has been determined by Zettnow. ${ }^{2}$ His data were taken at temperatures varying from $9.7^{\circ}$ to $35^{\circ}$. In the majority of determinations, however, the temperatures lie between $18^{\circ}$ and $22^{\circ}$, which we may assume as an ordinary range of room temperatures. He gives the following for a saturated water solution of chromium trioxide:

$\begin{array}{cccc}\begin{array}{c}\mathrm{CrO}_{3} . \\ \text { Per cent. }\end{array} & \text { Sp.gr. } & \begin{array}{c}\text { Gram-molecules } \\ \text { perliter. } \\ \text { I.7028 }\end{array} & \begin{array}{c}\text { Temp. } \\ \text { room }\end{array} \\ \text { results are the following: } & & \\ 63.2 \text { (saturated) } & \text { I.708 } & \text { Io.8 } & 25^{\circ} 4^{\circ} \\ 60 . & \text { I.667 } & \text { Io. } & 25^{\circ} 4^{\circ}\end{array}$

Let us consider the systems which can be built up from the three components, mercuric oxide, chromium trioxide and water.

${ }^{1}$ Cox, A. J.: Z. anorg. Chem. 40, 146 (1904).

2 Zettnow: Pogg. Ann. 143, 474 (1871); Jsb. 1871, 302. 
The equilibriums:

$$
\begin{aligned}
& { }_{3} \mathrm{HgO}+\mathrm{CrO}_{3} \cdot \mathrm{H}_{2} \mathrm{O} \stackrel{\mathrm{s} \longrightarrow \mathrm{HgO}}{\longrightarrow} \mathrm{CrO}_{3}+\mathrm{H}_{2} \mathrm{O} \\
& { }_{3} \mathrm{HgO} . \mathrm{CrO}_{3}+{ }_{2} \mathrm{CrO}_{3} \cdot \mathrm{H}_{2} \mathrm{O} \underset{\mathrm{H}}{\longrightarrow} 3 \mathrm{HgCrO}_{4}+{ }_{2} \mathrm{H}_{2} \mathrm{O}
\end{aligned}
$$

have been studied ${ }^{1}$ by considering the steps of hydrolysis of the neutral chromate. We can add to these a third, viz.:

$$
{ }_{3} \mathrm{HgCrO}_{4}+{ }_{3} \mathrm{CrO}_{3} \cdot \mathrm{H}_{2} \mathrm{O} \underset{\mathrm{O}}{\stackrel{\mathrm{N}}{\longrightarrow}} 3 \mathrm{HgCr}_{2} \mathrm{O}_{7}+{ }_{3} \mathrm{H}_{2} \mathrm{O} \text {. }
$$

In every reaction of this sort there is equilibrium of two opposing factors, the tendency to hydrolyze and the tendency to form complex salts. Each of these factors depends on the concentration of the acid, the former decreasing and the latter increasing with increasing concentration. When a system is in equilibrium these opposing factors a re equal. but as soon as one factor exceeds the other, reaction takes place.

The possibility of forming acid chromates of the heavy metals is limited only by the solubility of chromic acid. Experiment has shown that the tendency of mercuric bichromate to hydrolyze and its tendency to form from its components at $25^{\circ}$ just balance when the concentration of chromium trioxide has very nearly reached its saturation point. If this value were greater than the saturation concentration, at that temperature no acid chromate would exist in equilibrium with a solution.

\section{EXPERIMENTAL PART.}

All experiments described in this paper were carried on at $25^{\circ}$ by shaking in an electrically heated and electrically controlled thermostat. ${ }^{2}$

\section{TABULAR ABBREVIATIONS.}

$\mathrm{W}=$ The quantity of water in cubic centimeters which was added to the bottle.

$t=$ The time of shaking in days.

$\mathrm{G}=$ The number of cubic centimeters of solution, which were removed for the analyses.

$\mathrm{R}=$ The difference between the number of cubic centimeters in the beginning and the number of cubic centimeters used for the analyses.

$\mathrm{R}^{\prime}=\mathrm{R}$ corrected for the change of volume produced by the addition or abstraction of chromium trioxide from the solution during the experiment.

1 Cox: Z. anorg. Chem. 40, 146 (1904).

2 Young, S. W.: This Journal, 23, 327 (Igor). 
The numbers calculated for $25^{\circ} / 4^{\circ}$ and used in this paper are as follows :

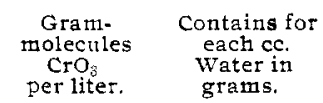

$10.8 \quad 0.63$

Saturated $\mathrm{H}_{2} \mathrm{CrO}$

$\left(\mathrm{H}_{2} \mathrm{O}, \mathrm{HgO}\right) \mathrm{CrO}_{3}$ [ $\mathrm{CrO}_{3}$ and $\mathrm{HgCr}_{2} \mathrm{O}_{5}$ in equilibrium]. II.42

$\left(\mathrm{H}_{2} \mathrm{O}, \mathrm{HgO}\right) \mathrm{CrO}_{3}\left[\mathrm{HgCr}_{2} \mathrm{O}_{7}\right.$ and $\mathrm{HgCrO}_{4}$ in equilibrium]

I0.46

$\left(\mathrm{H}_{2} \mathrm{O}, \mathrm{Bi}_{2} \mathrm{O}_{3}\right) \mathrm{CrO}_{3} \quad\left[\mathrm{Bi}_{2} \mathrm{O}_{3}, 4 \mathrm{CrO}_{3}\right.$ and $\mathrm{Bi}_{2} \mathrm{O}_{3}, 2 \mathrm{CrO}_{3}$ in

equilibrium]

7.8

$\left(\mathrm{H}_{2} \mathrm{O}, \mathrm{PbO}\right) \mathrm{CrO}_{3}\left[\mathrm{PbCr}_{2} \mathrm{O}_{7}\right.$ and $\mathrm{PbCrO}_{4}$ in equilibrium] 6.87

$\left(\mathrm{H}_{2} \mathrm{O}, \mathrm{PbO}\right) \mathrm{CrO}_{3}$ [ $\mathrm{CrO}_{3}$ and $\mathrm{PbCr}_{2} \mathrm{O}_{7}$ in equilibrium].. Io.8
0.606

0.648

0.747

0.78

0.63

$n=$ The titration value of I $\mathrm{cc}$. of the solution in cubic centimeters of $\mathrm{N} /{ }_{10} \mathrm{FeSO}_{4}$.

$m=$ Gram-molecules $\mathrm{CrO}_{3}$ per liter.

$\mathrm{Hg}, \mathrm{Bi}, \mathrm{Pb}$, etc. $=$ Grams $\mathrm{Hg}, \mathrm{Bi}, \mathrm{Pb}$, etc., in I cc. solution.

$\mathrm{Hg}^{\prime}, \mathrm{Bi}^{\prime}$, etc. $=$ Gram-molecules $\mathrm{Hg}, \mathrm{Bi}$, etc., per liter.

$q=$ The ratio of $\mathrm{HgO}, \mathrm{Bi}_{2} \mathrm{O}_{3}$, etc., to acid residue in the solid phases.

\section{METHOD OF ANALYSIS.}

With the exception of those of lead, the chromates investigated are all soluble in sulphuric acid. The chromium trioxide could therefore be at once determined by titration with ferrous sulphate solution, using potassium ferricyanide as indicator.

The chromates of lead are soluble in sodium hydroxide. To such a solution an excess of ferrous sulphate was added, the solution then acidified with sulphuric acid and titrated with standard potassium bichromate solution. ${ }^{1}$

The other metals were precipitated and weighed as sulphides. ${ }^{2}$

\section{MERCURIC BICHROMATE.}

In two preliminary experiments I/ Io gram-molecule mercuric oxide (Kahlbaum's preparation), 43/ 10o gram-molecule chromium trioxide and $25 \mathrm{cc}$. of a saturated solution of chromium trioxide; and I/Io gram-molecule mercuric oxide, 2/Io gram-molecule chromium trioxide and $25 \mathrm{cc}$. of a saturated solution of chromium trioxide, respectively, were shaken together in $50 \mathrm{cc}$. flasks. ${ }^{3}$ The data and results are contained in the following table:

1 This might easily be adapted to the volumetric determination of lead

2 Treadwell-Hall: Quant. Anal. Vol. II, I33, I4I.

${ }^{3}$ The results were saturated solutions of $\mathrm{CrO}_{3}$, saturated with mercuric bichromate; in other words, solutions in equilibrium with $\mathrm{CrO}_{3}$ and mercuric bichromate as solid phases. 
TABLE I.

$\begin{array}{ccccccccl}\quad \text { No. } & t . & \text { W. } & \text { G. } & \text { R. } & \mathrm{R}^{\prime} . & n . & m .1 & \text { Sp. gr. } \\ \mathrm{I} \ldots \ldots \ldots . . . \mathrm{I} & \mathrm{I} & \circ & 5 & 20 & 2 \mathrm{I} .2 & 343 & \mathrm{II} .43 & \mathrm{I} .8888 \\ 2 \ldots \ldots \ldots . .2 & 2 & 0 & 5 & 20 & 2 \mathrm{I} .2 & 342 & \mathrm{II} .4 \mathrm{I} & \mathrm{I} .888\end{array}$

To the remainder from Expt. 2 pure neutral mercuric chromate $^{2}$ was added in sufficient quantity to combine with the free acid in excess of the equilibrium concentration of mercuric bichromate. The product was the formation of more acid chromate as follows:

Mercuric chromate + chromium trioxide $\leftrightarrows$ mercuric bichromate.

The data and results are given in the following table:

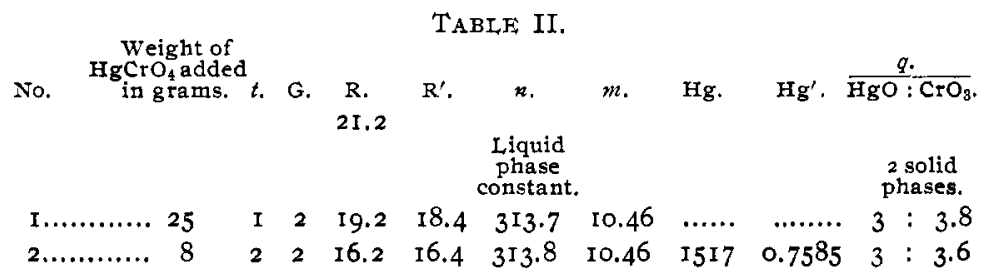

From the foregoing data we see that the reaction mercuric chromate + chromium trioxide $\rightarrow$ mercuric bichromate is in equilibrium when the solution contains 10.46 gram-molecules chromium trioxide $\left(\left[\mathrm{H}_{2} \mathrm{O},(\mathrm{HgO})_{x}\right] \mathrm{CrO}_{3}\right)$ per liter, i.e., at this concentration the tendency to hydrolyze just balances the tendency toward the formation of complex salts.

With these data at hand the preparation and identification of mercuric bichromate were not difficult. The remainder from Expt. I, Table I, was used as a starting point. The supernatant liquid was decanted off and the solid phases, which consisted of acid mercuric chromate and free chromic acid, were washed with a solution of the above-mentioned concentration, viz., xo.46 gram-molecules $\mathrm{CrO}_{3}\left(\left[\mathrm{H}_{2} \mathrm{O},(\mathrm{HgO})_{x}\right] \mathrm{CrO}_{3}\right)$ per liter, until all of the free chromic acid was washed out, $i . e$, until the wash liquid no longer increased in chromium trioxide content when shaken with the solid phase.

The salt which was of a deep crimson color was pressed between absorption plates and thoroughly dried at $65^{\circ}$. This substance upon analysis gave 50.2 per cent. $\mathrm{CrO}_{3}$; calculated for $\mathrm{HgCr}_{2} \mathrm{O}_{7}$, 48. I per cent.

${ }^{1}$ Gram-molecules $\left[\mathrm{H}_{2} \mathrm{O},(\mathrm{HgO}) x\right] \mathrm{CrO}_{3}$.

${ }^{2}$ Geuther: Ann. 106, 244; Cox: Loc. cit. p. I50. 
A high result is to be expected in view of the fact that the wash liquid is almost a saturated solution of chromic acid.

The concentration of chromium trioxide lying between that concentration which represents the hydrolytic dissociation pressure of chromium trioxide for mercuric bichromate and for neutral mercuric chromate was investigated.

In a $90 \mathrm{cc}$. bottle were placed 33.79 grams chromium trioxide and 25.9 grams mercuric oxide (Kahlbaum) and to these were added $30 \mathrm{cc}$. of a solution saturated with respect to mercuric bichromate and chromic acid as described in Expt. I, Table I. The data and results are contained in the following table:

TABLE III.

\begin{tabular}{|c|c|c|c|c|c|c|c|c|c|c|c|}
\hline No. & w. & $t$ & G. & $\mathrm{R}$. & $\mathrm{R}^{\prime}$ & $\begin{array}{c}n . \\
\text { Iiquid } \\
\text { phase } \\
\text { constant.. }\end{array}$ & $m$ & $\mathrm{Hg}$. & $\mathrm{Hg}^{\prime} \cdot \mathrm{I}$ & \multicolumn{2}{|c|}{$\frac{q \cdot}{\mathrm{HgO}: \mathrm{CrO}_{3}}$} \\
\hline I & 0 & & & 30 & 30. & 342.3 & II, $4 \mathrm{I}$ & & & \multicolumn{2}{|c|}{$3:>6$} \\
\hline 2 & 5 & I & 5 & 30 & 33.3 & 342.0 & II. 4 & & & \multicolumn{2}{|c|}{$3:>6$} \\
\hline & & & & & & & Ir. & & & 3: & 6 \\
\hline & & & & & & & 10.46 & & & 3: & 6 \\
\hline & & & & & & & & & & \multicolumn{2}{|c|}{2 solid phases } \\
\hline 3 & 5 & $\frac{3}{2}$ & 5 & 30 & 34.2 & $310.8^{1}$ & 10.36 & & & $3:$ & 5.30 \\
\hline 4 & 5 & 2 & 5 & 30 & 37. & $3 \pm 3.0^{1}$ & 10.43 & $0.15 \times 7$ & 0.7585 & $3:$ & 3.16 \\
\hline & & & & & & $\begin{array}{l}\text { Iiquid } \\
\text { phase } \\
\text { variable. }\end{array}$ & & & & \multicolumn{2}{|c|}{$\begin{array}{l}\text { I solid phase } \\
\text { of constant } \\
\text { composition. } \\
\text { Stable. }\end{array}$} \\
\hline 5 & 2 & 2 & 5 & 27 & 34.2 & 297.0 & 9.90 & & & 3: & 3 \\
\hline 6 & 0 & 2 & 5 & 22 & 29.2 & 296.8 & 9.89 & & & 3: & 3 \\
\hline 7 & I 5 & 2 & IO & 27 & 34.2 & 201.9 & 6.73 & & & 3: & 3 \\
\hline 8 & 10 & 2 & 5 & 32 & 39.2 & 156.0 & 5.20 & & & 3: & 3 \\
\hline 9 & 10 & 4 & 5 & 37 & 44.2 & 124.8 & 4.16 & & & 3: & 3 \\
\hline Io & 20 & $\mathbf{I}$ & 5 & 52 & 59.2 & 87.0 & 2.90 & & & 3: & 3 \\
\hline I I & 20 & 4 & 30 & 42 & 49.2 & 62.4 & 2.08 & & & 3: & 3 \\
\hline $\mathrm{I} 2$ & 20 & I & I 5 & 47 & 54.2 & 43.5 & 1.45 & & & $3:$ & 3 \\
\hline I 3 & 20 & I & IO & 52 & 64.2 & 30.8 & 1.035 & & & $3:$ & 3 \\
\hline
\end{tabular}

The table is continued from results at $50^{\circ} \mathrm{C}$. already published. ${ }^{2}$

$\begin{array}{rrllllllll}50 & 3 & 5 & 45 & 30.01 & 1.006 & 0.0203 & 0.1 & 3: & 3 \\ 5 & \mathrm{I} & 5 & 45 & 27.06 & 0.907 & 00185 & 0.092 & 3: & 3 \\ \text { IO } & \mathrm{I} & 5 & 50 & 22.1 \mathrm{I} & 0.740 & 0.0145 & 0.072 & 3: & 3\end{array}$

1 The value of $n$ or $m$ is a little small, depending upon $t$. These reactions reach equilibrium rather slowly, c. f. Table II.

${ }^{2} Z$, anorg. Chem. 40, r58, Tabelle VII; I52, Tabelle II (1904). 
TABLE III (continued).

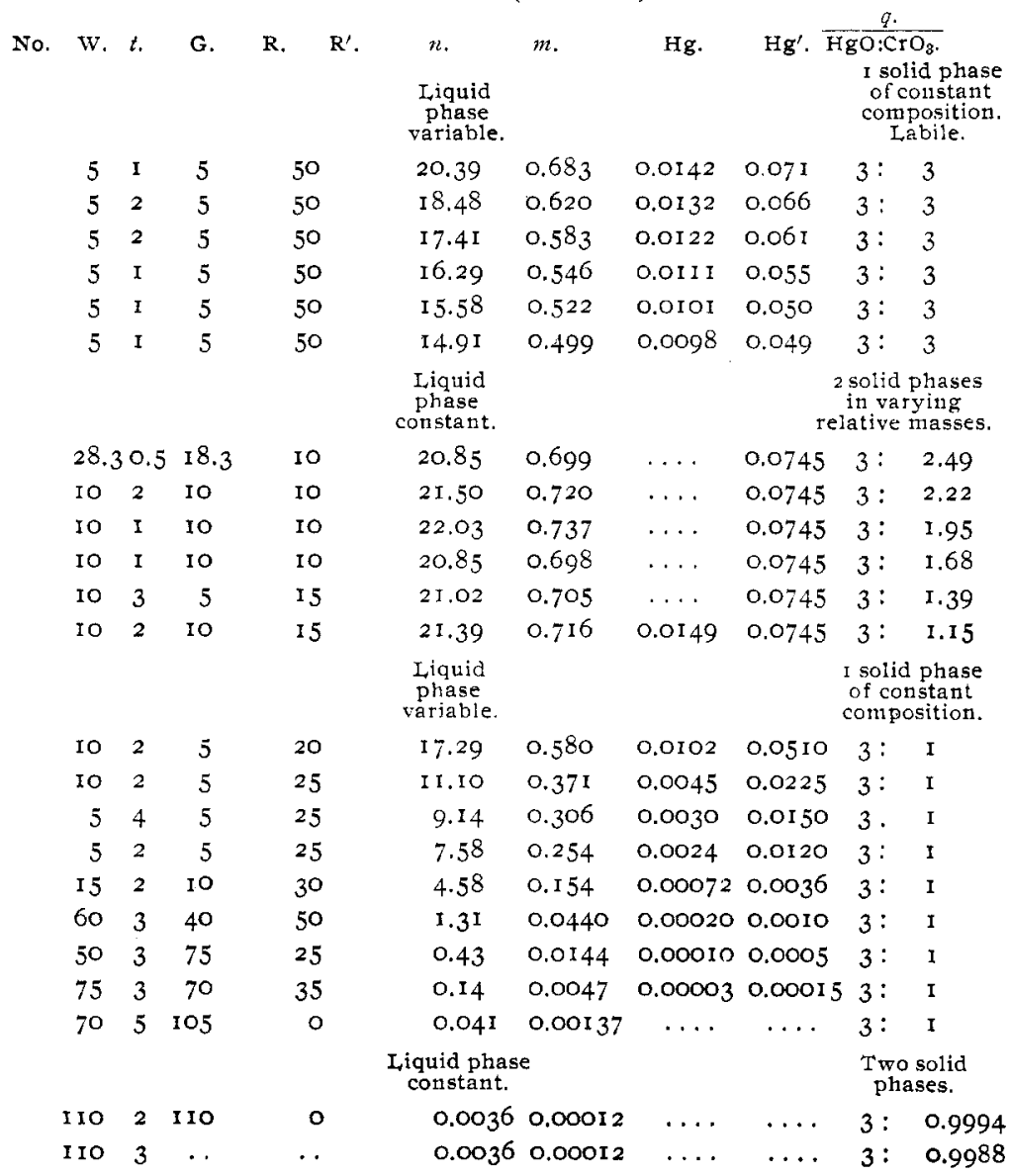

After Expt. I3, Table III, some of the solid phase which was of a light orange color was isolated, pressed between absorption plates and thoroughly dried. It gave 3I.6 per cent. $\mathrm{CrO}_{3}$; calculated for $\mathrm{HgCrO}_{4}$, 3 r.66 per cent.

This leaves no doubt as to its formula and as to its being the same salt as that used in the other experiments.

The hydrolytic dissociation pressure of chromium trioxide for neutral mercuric chromate at $25^{\circ}$ corresponds to 0.456 gram-molecule per liter. The basic mercuric chromate which has the formula ${ }_{3} \mathrm{HgO}$. $\mathrm{CrO}_{3}$ is a dark red powder. 


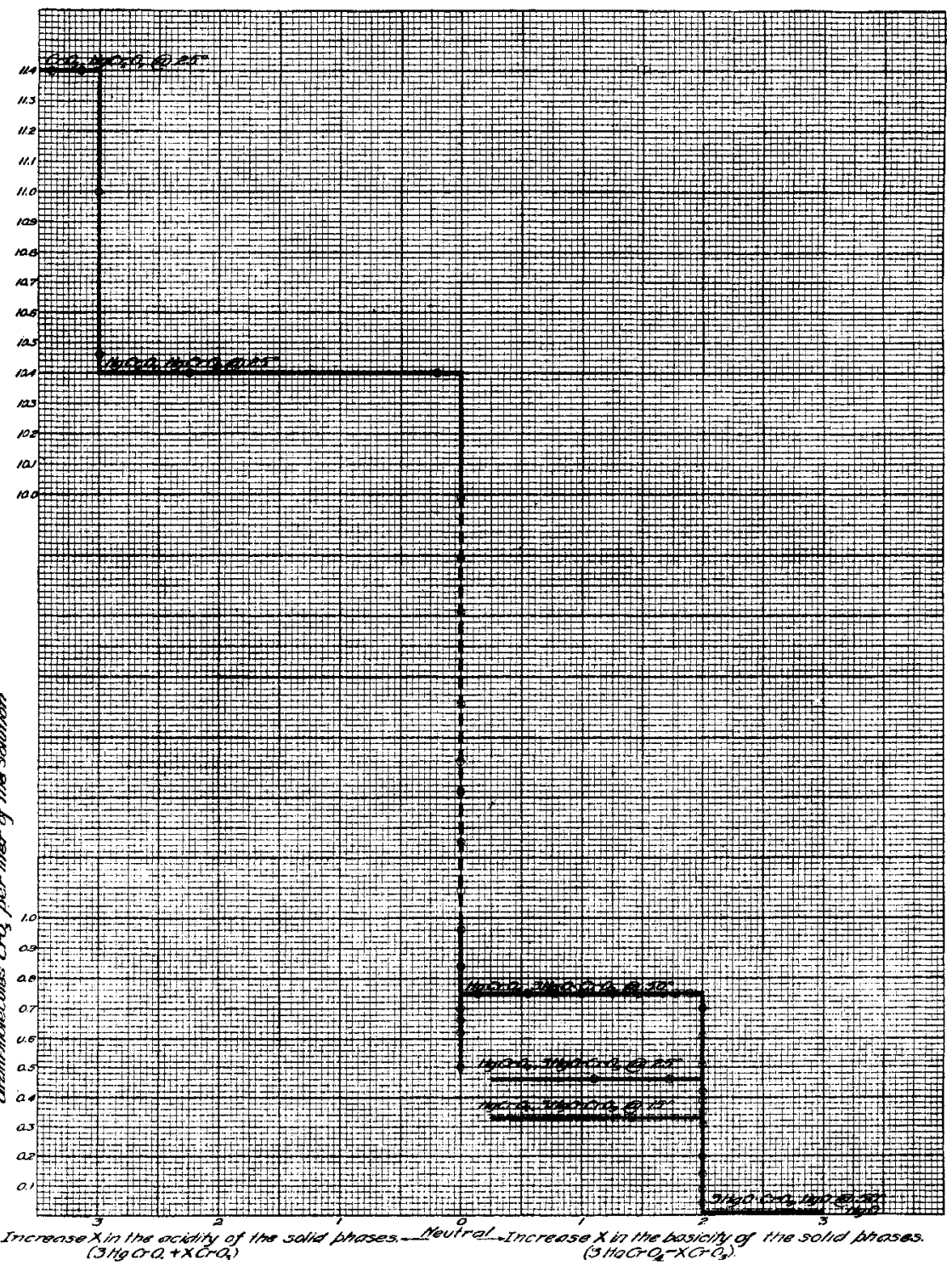

Fig. I 
When we plot the results of Table III, the above curve is obtained :

\section{LEAD BICHROMATE.}

It has already been shown that a bichromate is formed from a chromate and free chromic acid. Bichromates in solution are in general strongly acid toward litmus and act as strong acids toward many substances. This is made clear by the known fact that from a solution of bichromate, monochromate may be precipitated. ${ }^{1}$ By the addition of water to such a solution very often a precipitate of a more basic salt forms immediately. It is clear that in the solution there are not only bichromate ions but also monochromate ions and therefore free chromic acid. These general remarks find a good illustration in the lead salt, $\mathrm{PbCr}_{2} \mathrm{O}_{7}$. In the literature we find such statements as this: "With water lead bichromate decomposes with the formation of lead chromate."

Lead bichromate was prepared by grinding I gram-molecule of lead oxide with $2 \frac{1}{2}$ gram-molecules of chromic anhydride and enough saturated solution of chromium trioxide to cause it to triturate easily. The lead bichromate thus formed and the excess of chromium trioxide were shaken in the thermostat with a satirated solution of chromium trioxide to obtain the equilibrium constant of the system $\mathrm{PbCr}_{2} \mathrm{O}_{7}, \mathrm{CrO}_{3}$. The data and results are as follows:

TABLE IV.

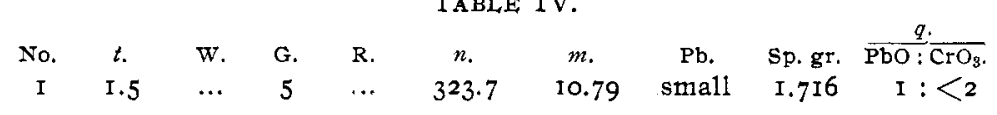

Preliminary experiments showed lead bichromate to be stable in a solution of chromium trioxide as dilute as $7 \mathrm{~m}$. The salt was obtained pure by dissolving out the free chromium trioxide and washing with $7 \mathrm{~m}$ chromium trioxide solution. The salt was pressed thoroughly between absorption plates and allowed to stand for a long time in a desiccator over calcium chloride. The salt upon analysis gave' $47 . \mathrm{I}_{4}$ and 47.09 per cent. $\mathrm{CrO}_{3}$; calculated for $\mathrm{PbCr}_{2} \mathrm{O}_{7}, 47.32$ per cent.

This salt is a brick-red crystalline powder. Under the microscope the crystals appeared very uniform and pure.

Twenty-five grams of the above analyzed lead bichromate were weighed into a $40 \mathrm{cc}$. bottle and $20 \mathrm{cc}$. of a solution of chromium

1 Abegg and Cox: Z. physik. Chem. 48, 725 (1904).

2 Preis and Raymann: Ber. 13, 340. 
trioxide saturated with lead bichromate and which showed a content of $8.196 \mathrm{~m}$ chromium trioxide were added. The data and results are given in the following table:

TABLe V.

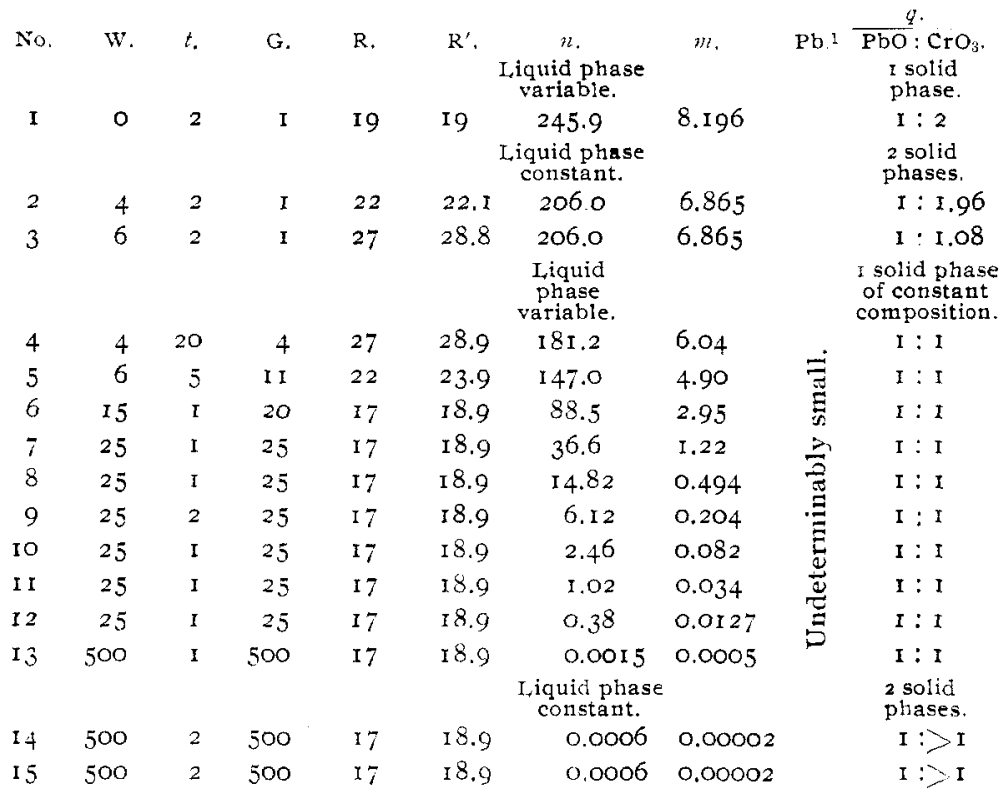

The method here employed is not applicable to the identification of the basic chromates of lead. When lead chromate and lead oxide are mixed in the presence of water there is a large swelling of the volume of the solid phases which is undoubtedly the result of the formation of a basic salt, probably $2 \mathrm{PbO} . \mathrm{CrO}_{3}$, commonly known as chrome red.

${ }_{3} \mathrm{PbO} \cdot \mathrm{CrO}_{3}$ exists in nature as the mineral melanochroite, phoenicochroite and is also described by Herman. ${ }^{2}$

After Expt. 12, Table V, some of the solid phase was isolated, pressed between absorption plates, and thoroughly dried. It gave $30.8 \mathrm{I}$ and 30.85 per cent. $\mathrm{CrO}_{3}$; calculated for $\mathrm{PbCrO}_{4}, 30.99$ per cent.

When the results in Tables IV and $\mathrm{V}$ are plotted the following

1 Calculated from electrical conductivity measurements of $\mathrm{PbCrO}_{4}+\mathrm{Aq}$; I liter dissolves $0.2 \mathrm{mg}$. $\mathrm{PbCrO}_{4}$ at $18^{\circ} \mathrm{C}$. Kohlrausch and Rose: $\mathrm{Z}$. physik. Chem. 12, 24 I.

${ }^{2}$ Pogg. Ann. 28, I62. 


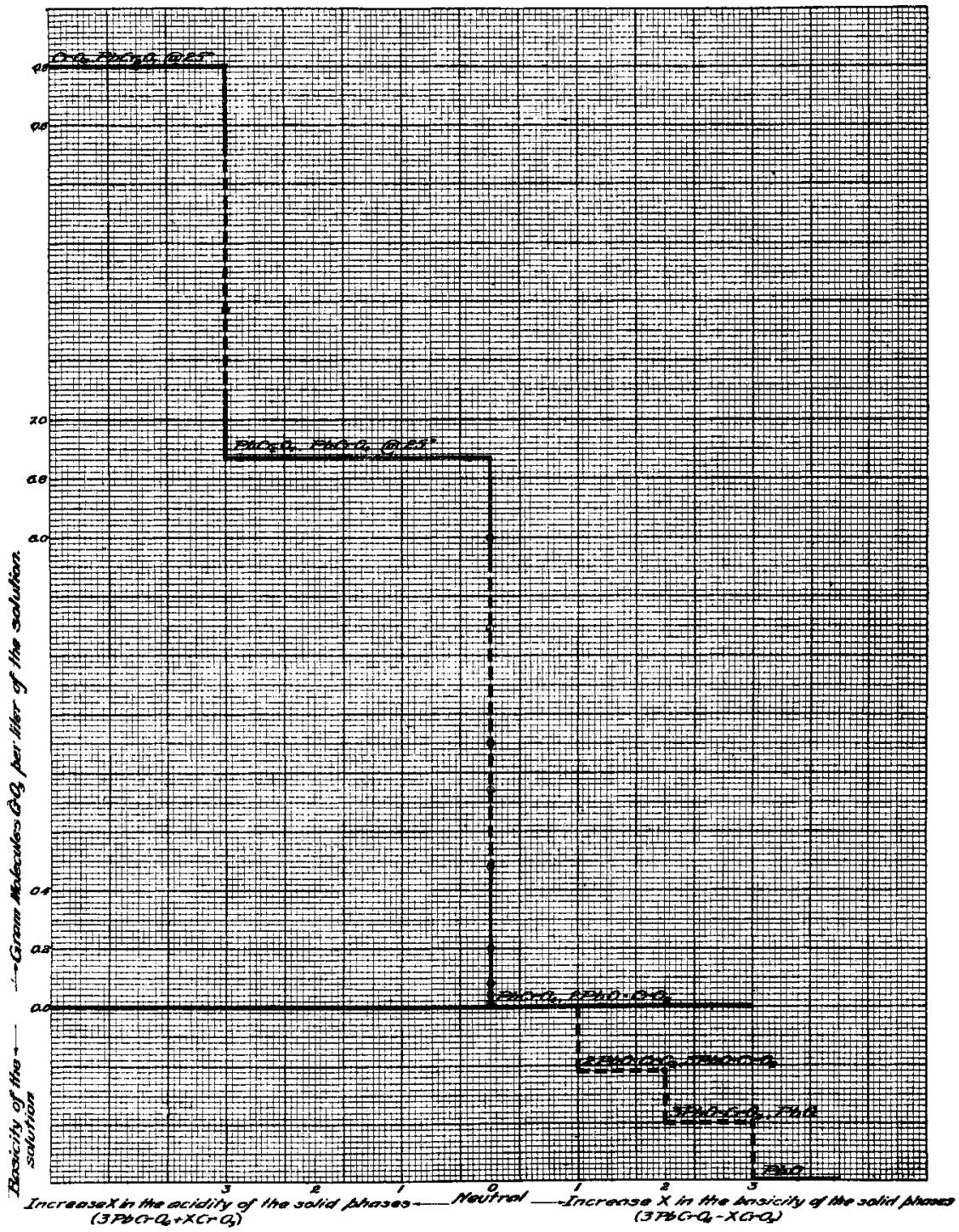

Fig. 2. 
curve is obtained, which shows conclusively that no salt exists between the bichromate and monochromate of lead.

\section{BISMUTH CHROMATE.}

Neutral bismuth chromate is unknown. There is a salt with a third less chromium trioxide than that corresponding to the net1tral chromate and one with a third more. The latter, the highest chromate of bismuth, was prepared by grinding together bismuth oxide and chromium trioxide in the molecular relations of one to slightly more than four, with just enough saturated chromium trioxide solution to make a paste. Afterwards, by the careful addition of water, it was possible to dissolve the grains of free acid and reach a dilution of chromium trioxide with which this bismuth salt was in equilibrium. This at room temperature is somewhat less than $\delta$ gram-molecules per liter or a solution of sp. gr. $=\mathrm{I} .5$.

Some of the salt prepared as above described was removed from the $8 \mathrm{~m}$ chromium trioxide solution to an absorption plate, allowed to stand twenty-four hours and finally dried and analyzed. No special precautions were taken to free the sample from mother-liquor and the analyses are therefore high with regard to chromium trioxide but are interesting from the standpoint of a "Note on the Efficiency of Centrifugal Purification," "when compared with two other pairs of analyses of the same salt given below.

The analysis gave 46.6 and 46.8 per cent. $\mathrm{CrO}_{3}$; calculated for $\mathrm{Bi}_{2} \mathrm{O}_{3} .4 \mathrm{CrO}_{8}, 46.3$ per cent.

In order to determine the hydrolytic dissociation pressure of the chromium trioxide from $\mathrm{Bi}_{2} \mathrm{O}_{3} \cdot 4 \mathrm{CrO}_{3}, 20$ grams of the above analyzed salt were shaken with $25 \mathrm{cc}$. of the mother-liquor $=7.5 \mathrm{~m}$ chromium trioxide. The data and results are as follows:

TABLE VI.

\begin{tabular}{|c|c|c|c|c|c|c|c|c|c|c|}
\hline No. & w. & $t$ & G. & R. & $\mathbf{R}^{\prime}$ & $\begin{array}{l}n . \\
\text { uid phs } \\
\text { onstant }\end{array}$ & $m$ & $\mathrm{Bi}$. & $\mathrm{Bi}^{\prime}$ & $\begin{array}{l}\frac{q .}{\mathrm{B}_{2} \mathrm{O}_{3}}: \mathrm{CrO}_{3} . \\
\text { 2 solid } \\
\text { phases. }\end{array}$ \\
\hline I & 0 & I & I & 24 & $24 \% / 4$ & 232.2 & 7.74 & 0.016 & 0.04 & $\mathrm{I}: 3.4$ \\
\hline 2 & 0 & 2 & I & 23 & $23 \frac{1}{4}$ & 233.8 & 7.794 & 0.016 & 0.04 & $r: 3.3$ \\
\hline 3 & IO & & 0 & 33 & $34 / 2$ & & & & & $I: 2$ \\
\hline
\end{tabular}

The salt being completely hydrolyzed according to the reaction $\mathrm{Bi}_{2} \mathrm{O}_{3.4} \mathrm{CrO}_{3}$ $\rightleftarrows \mathrm{Bi}_{2} \mathrm{O}_{3}, 2 \mathrm{CrO}_{3}+{ }_{2} \mathrm{CrO}_{3}, 8$ grams of $\mathrm{CrO}_{3}$ were added so as to approach the 1 T. W. Richards: This Journal, 27, 104 (1905). 
equilibrium from the other direction as shown by the reaction $\mathrm{Bi}_{2} \mathrm{O}_{8} \cdot 2 \mathrm{CrO}_{8}+$ ${ }_{2} \mathrm{CrO}_{3} \stackrel{-m}{-} \mathrm{Bi}_{2} \mathrm{O}_{8} \cdot 4 \mathrm{CrO}_{3}$.
4
$361 / 2$
234.0
7.80
0.016
$0.04 \quad \mathrm{I}: 2.5$

The hydrolytic dissociation pressure of chromium trioxide from $\mathrm{Bi}_{2} \mathrm{O}_{3} \cdot 4 \mathrm{CrO}_{3}$ is $7.794-7.80 \mathrm{~m}$. With these data at hand the purest possible $\mathrm{Bi}_{2} \mathrm{O}_{3} \cdot 4 \mathrm{CrO}_{3}$ was obtained. Twenty-five grams of the above analyzed salt and $22 \mathrm{cc}$. of a solution of chromium trioxide saturated at $25^{\circ}$, which analyzed $10.76 n$, were placed in a $50 \mathrm{cc}$. bottle. The data and results are contained in the following table: TABLE VII.

\begin{tabular}{|c|c|c|c|c|c|c|c|c|c|}
\hline \multirow[b]{2}{*}{ No. } & \multirow[b]{2}{*}{ w. } & & \multirow{2}{*}{ 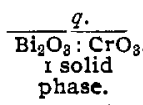 } \\
\hline & & $t$ & G. & R. & $\begin{array}{l}n . \\
\text { Liquid phase } \\
\text { variable. }\end{array}$ & $m$. & Bi. & $B \mathfrak{i}^{\prime}$ & \\
\hline I & 0 & 6 & 2 & 20 & 335.4 & II. 17 & 0.04 & O.I & I $: 4$ \\
\hline 2 & 5 & 3 & 2 & 23 & 267.8 & 8.93 & & $\ldots .$. & I $: 4$ \\
\hline & 3 & 3 & I & 25 & 237.4 & 7.92 & 0.016 & 0.04 & I $: 4$ \\
\hline
\end{tabular}

The last dilution carries the concentration of the chromium trioxide close to the equilibrium point and it is as far as it is safe to go.

It is evident that the only wash liquid permissible for this salt is a solution of chromium trioxide containing not less than 7.8 gram-molecules per liter. If it is possible to free the salt from the mother-liquor, it is then in the pure form. Two methods were tried, viz.; first, by pressing with a very considerable pressure between clay absorption plates for some hours; second, by centrifuging in a platinum basket for a few hours and finally in both cases drying over calcium chloride. Sulphuric acid as a drying agent was tried, but as it caused the salt to decolorize somewhat the method was abandoned.

The sample obtained by the first method gave 46.0 and 46.2 per cent. $\mathrm{CrO}_{3}$; calculated for $\mathrm{Bi}_{2} \mathrm{O}_{3} \cdot 4 \mathrm{CrO}_{3}, 46.3$ per cent.

This sample may have been contaminated with a very small trace of basic chromate as the pressing had to be done in the open air. The small amount of mother-liquor $\left(\mathrm{CrO}_{3}\right)$ would attract moisture from the air until its concentration was lowered below the hydrolytic dissociation pressure for $\mathrm{Bi}_{2} \mathrm{O}_{3} \cdot 4 \mathrm{CrO}_{3}$, whereby a small amount of $\mathrm{Bi}_{2} \mathrm{O}_{3} \cdot 4 \mathrm{CrO}_{3}$ was hydrolyzed and the chromium trioxide liberated absorbed in the plates together with the motherliquor.

1 By a series of experiments it has been ascertained that equilibrium is complete in forty-eight hours, but a period of three days has been consistently used in order that there may be no question. 
The sample obtained by the second method gave, upon analysis, 46.2 and 46.3 per cent. $\mathrm{CrO}_{3} ; 54 . \mathrm{I}$ and 53.8 per cent. $\mathrm{Bi}_{2} \mathrm{O}_{3}$; calculated for $\mathrm{Bi}_{2} \mathrm{O}_{3} .4 \mathrm{CrO}_{3}, 46.3$ and 53.7 per cent.

This salt is a splendid orange vermillion and when perfectly dry is fairly stable in the air.

Muir ${ }^{1}$ undoubtedly obtained the same salt, to which he assigned the formula $\mathrm{Bi}_{2} \mathrm{O}_{3} \cdot{ }_{4} \mathrm{CrO}_{3} \cdot \mathrm{H}_{2} \mathrm{O}$. I cannot but doubt the accuracy of his numbers. His sample was probably not perfectly dry. Even the analyses from which he makes his deductions contain only two-thirds of the water necessary to make up the theoretical amount.

This salt, as is to be expected, may be formed byboiling the lower chromate with nitric acid.

The reaction might be represented as follows:

$$
\mathrm{Bi}_{2} \mathrm{O}_{3} \cdot 2 \mathrm{CrO}_{3}+4 \mathrm{HNO}_{3}=\mathrm{Bi}_{2} \mathrm{O}_{3} \cdot 4 \mathrm{CrO}_{3}+2 \mathrm{Bi}\left(\mathrm{NO}_{3}\right)_{2} \text {. }
$$

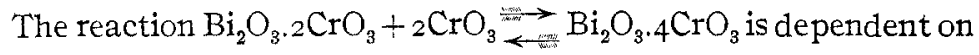
the acid concentration. If part of this concentration is made up of nitric acid, it is equally effective. In the same manner the hydrolysis of $\mathrm{Bi}_{2} \mathrm{O}_{3} \cdot 4 \mathrm{CrO}_{3}$ will not take place in a solution of chromic acid less than $7.8 \mathrm{~m}$ if the required acid concentration is made up of nitric acid.

Table VII begins with the concentration where chromium trioxide and $\mathrm{Bi}_{2} \mathrm{O}_{3} .4 \mathrm{CrO}_{3}$ are in equilibrium and the concentration of the chromium trioxide is variable in direct proportion to the dilution. To have that degree of freedom there could have been but one solid phase. This shows therefore that $\mathrm{Bi}_{2} \mathrm{O}_{3} \cdot 4 \mathrm{CrO}_{3}$ is the highest chromate of bismuth. The possibility of bichromate is excluded, owing to the limited solubility of chromium trioxide which makes it impossible to attain the hydrolytic dissociation pressure of such a salt.

Starting with $\mathrm{Bi}_{2} \mathrm{O}_{3} \cdot 4 \mathrm{CrO}_{3}$, it is possible to isolate and analyze the more basic chromates. To do this 50 grams of the above analyzed salt were weighed into a roo $\mathrm{cc}$. bottle and a solution of chromium trioxide saturated with $\mathrm{Bi}_{2} \mathrm{O}_{3} \cdot 4 \mathrm{CrO}_{3}$ at room temperature was added. The data and results are given in the following table:

${ }^{1} \mathrm{~J}$. Chem. Soc. 30, I7 (1876). 
TABLE VIII.

\begin{tabular}{|c|c|c|c|c|c|c|c|c|c|c|}
\hline & & & & & & & & & & \\
\hline No. & w. & $t$. & G. & R. & $\mathbf{R}^{\prime}$ & $\begin{array}{l}n . \\
\text { quid phase } \\
\text { rariable. }\end{array}$ & $m$. & Bi. & $B i^{\prime}$. & $\begin{array}{c}\frac{q \cdot}{\mathrm{Bi}_{2} \mathrm{O}_{8}: \overline{\mathrm{CrO}}_{3} .} \\
\text { I solid } \\
\text { phase. }\end{array}$ \\
\hline & & & & 40 & 40. & 229.6 & $7.66^{1}$ & 0.016 & 0.04 & $I: 4$ \\
\hline & & & & & & $\begin{array}{l}\text { quid phase } \\
\text { constant. }\end{array}$ & & & & $\begin{array}{l}2 \text { solid } \\
\text { phases. }\end{array}$ \\
\hline I & 0 & IO & 2 & $3^{8}$ & 38. & 233.5 & 7.783 & 0.016 & 0.04 & I : 3.9 \\
\hline 2 & 4 & 3 & 2 & 40 & 41.36 & 233.8 & 7.793 & 0.016 & 0.04 & $I: 3.18$ \\
\hline 3 & 2 & 7 & 2 & 40 & 42.04 & 234.2 & 7.807 & 0.016 & 0.04 & $I: 2.82$ \\
\hline 4 & 4 & 5 & 2 & 42 & 45.40 & 234.3 & 7.810 & 0.016 & 0.04 & $1: 2.11$ \\
\hline & & & & & & $\begin{array}{c}\text { I,iquid } \\
\text { phase } \\
\text { variable. }\end{array}$ & & & & $\begin{array}{l}\text { I solid phase } \\
\text { of constant } \\
\text { composition. }\end{array}$ \\
\hline 5 & 4 & 4 & 2 & 44 & 48.75 & 216.5 & 7.22 & & & $1: 2$ \\
\hline 6 & 0 & 3 & 2 & 42 & 46.75 & 216.6 & 7.22 & & & I : 2 \\
\hline 7 & 4 & 10 & 2 & 44 & 48.75 & 198.6 & 6.62 & & & I : 2 \\
\hline 8 & 20 & 4 & 25 & 39 & 43.75 & 140.0 & 4.666 & & & $1: 2$ \\
\hline 9 & 25 & 2 & 25 & 39 & 43.75 & 88.0 & 2.933 & $\nexists$ & & I : 2 \\
\hline 10 & 42 & 2 & 57 & 24 & 28.75 & 44.1 & I. 470 & 吾 & & $1: 2$ \\
\hline II & 50 & 2 & 40 & 34 & 38.75 & 16.05 & 0.535 & के & & $1: 2$ \\
\hline 12 & 40 & 2 & 20 & 54 & $5^{8.75}$ & 7.89 & 0.263 & $\frac{2}{0}$ & & $1: 2$ \\
\hline 13 & 20 & 2 & 30 & 44 & 48.75 & 5.88 & 0.196 & . & & I : 2 \\
\hline 14 & 30 & 2 & 40 & 34 & $3^{8.75}$ & 3.57 & 0.119 & 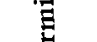 & & $I: 2$ \\
\hline 15 & 40 & 2 & 45 & 29 & 33.75 & 1.64 & $0.05^{8}$ & 范 & & I $: 2$ \\
\hline 16 & 50 & I & 35 & 44 & 48.75 & 0.69 & 0.023 & 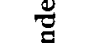 & & I: 2 \\
\hline 17 & 40 & 2 & 45 & 39 & 43.75 & 0.39 & 0.013 & 5 & & $I: 2$ \\
\hline 18 & 45 & 2 & 60 & 24 & 28.75 & 0.18 & 0.006 & & & $x: 2$ \\
\hline 19 & 60 & 2 & 55 & 29 & 33.75 & 0.06 & 0.002 & & & $1: 2$ \\
\hline 20 & 55 & 2 & 60 & 24 & 28.75 & 0.018 & 0.0006 & & & $I: 2$ \\
\hline $2 I$ & 60 & 2 & 75 & 9 & 13.75 & 0.006 & 0.0002 & & & $I: 2$ \\
\hline & & & & & & $\begin{array}{l}\text { iquid phase } \\
\text { constant. }\end{array}$ & & & & $\begin{array}{l}\text { 2 solid } \\
\text { phasey. }\end{array}$ \\
\hline 22 & 400 & 2 & 400 & 9 & $\mathrm{I} 3.75$ & 0.0003 & 0.00001 & & & $I:>2$ \\
\hline 23 & 400 & 2 & 400 & & & 0.0003 & 0.00001 & & & $I:>2$ \\
\hline
\end{tabular}

After Expt. 20 some of the salt was removed and thoroughly dried. It was found to contain no water. It analyzed as follows: $\mathrm{CrO}_{3}, 30.14$ and 29.95 per cent.; $\mathrm{Bi}_{2} \mathrm{O}_{3}, 70.02$ per cent.; calculated for $\mathrm{Bi}_{2} \mathrm{O}_{8} \cdot 2 \mathrm{CrO}_{3}$, 30.I and 69.9 per cent.

This salt is an orange-yellow. This formula $\mathrm{Bi}_{2} \mathrm{O}_{3} \cdot 2 \mathrm{CrO}_{3}$ was assigned by Löwe ${ }^{2}$ who has described this salt very accurately.

A large number of chromates of bismuth have been described in the literature, but many of them can probably be classified as impure specimens of one or the other of these salts or mixtures.

1 Room temperature.

3 J. pr. Chem. 67,463 (1856). 
The salts ${ }_{3} \mathrm{Bi}_{2} \mathrm{O}_{3} \cdot 7 \mathrm{CrO}_{3}$ and ${ }_{5} \mathrm{Bi}_{2} \mathrm{O}_{3}$. I I $\mathrm{IrO}_{3}$ described by Muir ${ }^{1}$ are undoubtedly impure samples of $\mathrm{Bi}_{2} \mathrm{O}_{3} \cdot 2 \mathrm{CrO}_{3}$.

Pearson ${ }^{2}$ has even assigned the formula $\mathrm{Bi}_{2} \mathrm{O}_{3} \cdot \mathrm{CrO}_{3}$ to this ordinary orange-yellow salt which is obtained by precipitating bismuth nitrate with potassium dichromate but the accuracy of his numbers has already been doubted. ${ }^{3}$

The salt described by Löwe, ${ }^{3}$ to which he assigns the formula ${ }_{3} \mathrm{Bi}_{2} \mathrm{O}_{3} \cdot{ }_{2} \mathrm{CrO}_{3}$, may be, judging from his method of preparation and in the light of the present investigation, a mixture of $\mathrm{Bi}_{2} \mathrm{O}_{3}$. $\mathrm{CrO}_{3}$ and $\mathrm{Bi}_{2} \mathrm{O}_{3}$. Owing to the practically zero or perhaps negative value for the hydrolytic dissociation of $\mathrm{Bi}_{2} \mathrm{O}_{3} \cdot 2 \mathrm{CrO}_{3}$, the methods employed in this research are not applicable to the identification of the chromates of bismuth containing less $\mathrm{CrO}_{3}$ than $\mathrm{Bi}_{2} \mathrm{O}_{3}$. ${ }_{2} \mathrm{CrO}_{3}$. As for those containing more $\mathrm{CrO}_{3}$ than $\mathrm{Bi}_{2} \mathrm{O}_{3} \cdot{ }_{2} \mathrm{CrO}_{3}$ there exists at $25^{\circ}$ but the one, viz., $\mathrm{Bi}_{2} \mathrm{O}_{3} \cdot 4 \mathrm{CrO}_{3}$. The salt described by Pearson as $\mathrm{Bi}_{2} \mathrm{O}_{3} \cdot 3 \mathrm{CrO}_{3}$ is undoubtedly an impure specimen of this salt.

When the results of Tables VII and VIII are plotted, the following curve is obtained, which shows the relationship which exists between these two salts.

\section{SUMMARY.}

(1) By investigations from the standpoint of the phase rule, it is possible to distinguish the existing salts from the mixtures of two salts in undefined proportions which have found their way into the chemical literature as chemical compounds.

(2) The phase rule states that the number of components less the number of phases plus two equals the number of degrees of freedom. Systems like those under discussion in this paper when two solid phases are present have one degree of freedom. The components are: the oxide of the heavy metal; chromium trioxide and water. The phases are: two chromates, solution, and vapor. It is only necessary to work at constant temperature to attain complete equilibrium. At constant temperature the only possible variation from the state of equilibrium is in the disappearance of one of the chromates (one solid phase), at which

1 J.pr. Chem. 3I, 24 ( 1877 ).

2 Phil. Mag. [4], II, 204.

${ }^{3}$ J. pr. Chem. 67, 288 (1856).

* Pearson: Phil. Mag. [4], Ir, 206. 


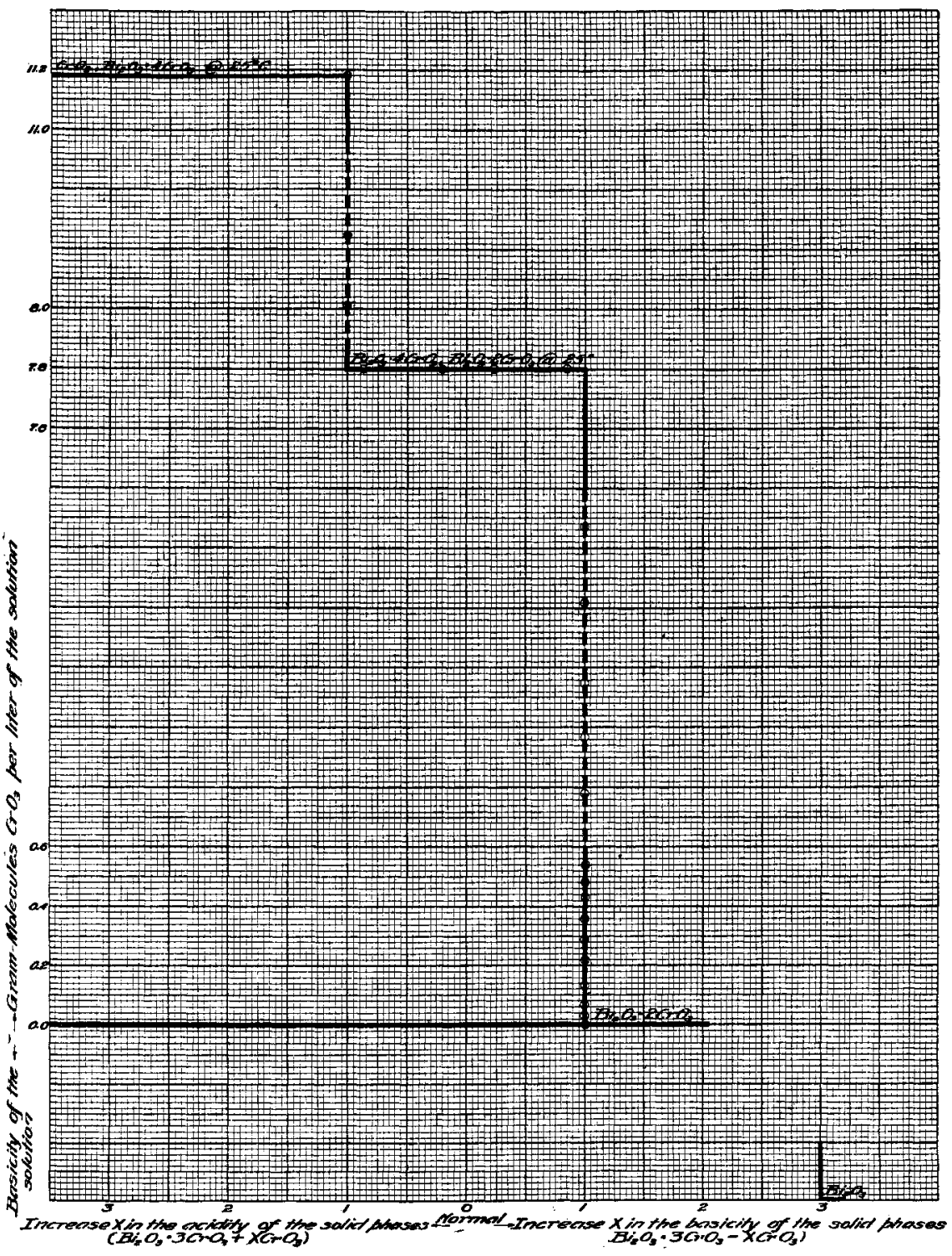

Fig. 3 . 
time the concentration of the solution will become variable in direct proportion to its dilution, or we can state conversely that at constant temperature, the changing of the acid concentration in proportion to the dilution is indicative of one and only one solid phase-one chemical individual.

(3) The two highest chromates of mercury, lead and bismuth, are respectively $\mathrm{HgCr}_{2} \mathrm{O}_{7}, \mathrm{HgCrO}_{4}, \mathrm{PbCr}_{2} \mathrm{O}_{7}, \mathrm{PbCrO}_{4}, \mathrm{Bi}_{2} \mathrm{O}_{3} \cdot 4 \mathrm{CrO}_{3}$ and $\mathrm{Bi}_{2} \mathrm{O}_{3} \cdot 2 \mathrm{CrO}_{3}$.

(4) In accord with the phase rule each of these salts has a certain hydrolytic dissociation pressure, $i$. e., a certain minimum acid concentration below which it is not stable. Without a knowledge of these concentrations it is not, in general, possible to prepare the salts pure.

The hydrolytic dissociation pressures for the above salts in gram-molecules of $\mathrm{CrO}_{3}$ per liter at $25^{\circ}$ are:
I. $\mathrm{HgCr}_{2} \mathrm{O}_{7}$ 10.46
$\mathrm{HgCrO}$
0.46
2. $\mathrm{PbCr}_{2} \mathrm{O}_{2}$
6.87
$\mathrm{PbCrO}_{4}$
0.00002
3. $\mathrm{Bi}_{2} \mathrm{O}_{3} \cdot 4 \mathrm{CrO}$
7.80
$\mathrm{Bi}_{2} \mathrm{O}_{3} .2 \mathrm{CrO}$
0.00001

All of these salts require an acid of the above concentration as a minimum for their formation and to maintain their stability.

(5) The existence in the pure form of the second highest chromates is limited by a maximum acid concentration equal to the minimum concentration of the next higher chromate, while the existence of the highest chromates is limited only by their own solubility and that of chromium trioxide. This is easily seen from the figures in the text.

LELAND STANFORD, JR, UNIVERSTTY, CALTF, March, 1906.

[CONTRIBUTIONS FROM THE HAVEMEYER CHEMICAL LABORATORY OF NEW YORK UNIVERSITY.]

\section{THE CHANGE FROM GREEN TO VIOLET IN CHROMIUM CHLORIDE SOLUTION.}

BX ARThUR B. LAMr.

Received October 27, 1906.

Weinland and Koch ${ }^{1}$ have recently disclosed some interesting facts regarding the precipitability of the chlorine in the green 1 Weinland and Koch: Z. anorg. Chem. 39, 256 ( 1904). 